\title{
INTERVENÇÕES VISUAIS URBANAS: SENSIBILIDADE(S) EM ARTE, GRAFITE E PICHAÇÃO
}

\author{
INTERVENCIONES VISUALES URBANAS: SENSIBILIDAD(ES) EN EL ARTE, \\ GRAFFITI Y PICHAÇ $\tilde{A} O$ \\ VISUAL URBAN INTERVENTIONS: SENSIBILITIES IN ART, GRAFFITI AND \\ PICHAÇÃO
}

http://dx.doi.org/10.1590/1807-0310/2017v29169375

\author{
Adolfo Pizzinato e Pedro de Castro Tedesco \\ Pontificia Universidade Católica do Rio Grande do Sul, Porto Alegre/RS, Brasil \\ Cristiano Hamann \\ Universidade Federal do Rio Grande do Sul, Porto Alegre/RS, Brasil
}

\begin{abstract}
RESUMO
$\mathrm{O}$ artigo propõe-se a discutir sentidos e significados implicados em narrativas de transeuntes acerca de três modalidades de intervenções visuais urbanas: a Arte Chancelada, o Grafite e a Pichação. Foram realizadas entrevistas com vinte e um(a) participantes não produtores(as) desses tipos de intervenção. A ênfase da discussão se dá nos aspectos psicossociais dessas três modalidades, atentando para seus diferentes regimes de visibilidade de produção cultural e as significações que as qualificam e estabelecem campos de diferenciação entre elas. Além de apresentar as principais características elencadas nas entrevistas para cada um dos tipos de intervenção se discute, através da noção de Partilha do Sensível de Jacques Rancière, os eixos que sustentavam dinâmicas de autorização/legitimidade para sua elaboração no tecido social da cidade: a consistência do ato, uso dos espaços, linguagem comum e a noção de representatividade.
\end{abstract}

Palavras-chave: grafite; arte urbana; pichação.

\section{RESUMEN}

El artículo se propone a discutir sentidos y significados implicados en narrativas de pasantes acerca de tres modalidades de intervenciones visuales urbanas: el Arte Legitimado, el Grafiti y la Pichação (pintadas). Han sido realizadas entrevistas con veintiuna personas, no productoras de estos tipos de intervención urbana. El énfasis de la discusión se da en los aspectos psicosociales de estas tres modalidades, atentando para sus distintos regímenes de visibilidad de producción cultural y las significaciones que las califican y establecen las distinciones entre ellas. Además de presentar las principales características en cada tipo de intervención, se discute, a través de la noción de Reparto del Sensible de Jacques Rancière, los ejes que sostienen las dinámicas de autorización/ legitimidad para su elaboración en el tejido social de la ciudad: la consistencia del acto; uso de los espacios; lenguaje común y la noción de representatividad.

Palabras-clave: grafiti; arte urbana; pintadas.

\begin{abstract}
The manuscript aims to discuss ways and meanings involved in passer-by narratives on three modalities of urban visual interventions: Legitimated Art, Graffiti and Pichação (spraypainting). Twenty people that do not produce these types of urban intervention were interviewed. The emphasis of the discussion is about the psychosocial aspects of these three modalities, drawing attention to its various regimes of cultural production visibility and the meanings that qualify and establish the distinctions between them. In addition to presenting the main features in each type of intervention, the axes that support the dynamics of authorization / legitimacy for its elaboration in the social fabric of the city are discussed, such as consistency of the act, use of space, common language and representativeness, based on the notion of sharing the sensitive of Jacques Rancière.
\end{abstract}

Keywords: graffiti; urban arts; spraypainting. 


\section{Introdução}

Intervenções visuais urbanas têm feito parte do cotidiano das cidades e impactado, de diversas formas, os espaços de convivência e passagem nessas geografias. Para além das intervenções da dita Arte Chancelada ${ }^{1}$, fenômenos como o grafite e a pichação são cada vez mais presentes e geram tensões no que se refere a sua existência e propagação. Exemplo da emergência dessas questões é a atual "declaração de guerra" contra grafiteiros(as) e, especialmente, pichadores(as) na cidade de São Paulo e as operações de dilapidação de patrimônio público operadas no mandato do atual prefeito $^{2}$. A pichação, em específico, é uma forma de intervenção particular no país (Bastianello, 2015), com um caráter de distinção marcado entre essa, o Grafite e a Arte Chancelada. Assim como essa particularidade nacional faz atentar para outras formas de significação das intervenções visuais, demanda também uma discussão a luz de uma perspectiva compreensiva, qualitativa e localizada.

No que se refere ao Grafite e a Pichação vemos que, no Brasil, a pesquisa sobre essas manifestações visuais urbanas varia enormemente. A construção dessas intervenções na paisagem com foco nas relações de poder que engendram (Silva, 2010) e no tensionamento à noção de propriedade e suas articulações com o direito à expressão (Paixão, 2011) são algumas delas. Outros trabalhos têm discutido a Pichação e o Grafite enquanto formas, ou não, de Arte, elaborando problematizações acerca das dimensões artísticas nesse tipo de intervenção (Verano, 2013). Enfatizam aspectos relacionados à existência de códigos e regras grupais, salientando a heterogeneidade dos diferentes movimentos nas cidades brasileiras (Munhoz, 2014) ou analisando a interface entre produção visual e criminalidade (Larruscahim \& Schweuizer, 2014; Piccoli, 2014). Há, também, trabalhos que problematizam as estratégias pedagógicas por parte do Poder Público (Viegas \& Saraiva, 2015) e as relações de gênero envolvidas nesses campos de sociabilidade (Hamann, MaracciCardoso, Tedesco, \& Pizzinato, 2013).

A despeito dos focos diferentes nesses campos analíticos, tanto a Pichação quanto o Grafite figuram especialmente dentro das grandes cidades e encontrase em interface com os processos tradicionalmente relacionados à urbanização contemporânea: relações pautadas por velocidade, comunicação em massa e atravessamentos do capital. Se compreendermos o contexto das urbes pela via do reconhecimento de processos de espetacularização e de gentrificação (Brito \& Jacques, 2009; Leite, 2007) atentamos aos atravessamentos mercadológicos, a lógica de consumo que se engendra, os processos de higienização social, de segregação e de elitização de espaços de convivência urbana. Consoante à reflexão empreendida pelos Situacionistas (grupo de artistas, arquitetos e urbanistas) sobre o processo de urbanização na década de 1950-60, os quais já apontavam para um caráter de espetacularização da cidade - especialmente Guy Debord (1997) -, compreende-se que as urbes contemporâneas, de uma maneira geral, apresentam diversas dimensões de ação vinculadas à lógica de mercado. Exemplo desse movimento são os projetos públicos que se voltam para uma compreensão da cidade enquanto todo homogêneo, unitário e consensual (Pena \& Wan-Dall, 2012), compreensão que tem suscitado problemas urbanísticos e legais cuja dimensão subjetiva não é levada em conta.

A urbanização crescente, os tipos de vinculação das populações com o espaço público e os investimentos governamentais no processo de estruturação do território são pauta necessária de discussão e figuram também quando analisamos o contexto de intersecção Pichação/Grafite/Artes visuais chanceladas nas cidades. Aspectos como os registros de reclamação à prefeitura de Porto Alegre, por exemplo, são consideravelmente maiores nos casos de Pichação e as representações midiáticas no município reiteram-na como sinônimo de periculosidade, violência e crime ${ }^{3}$. Uma ação identificada em várias cidades e que parece coerente com esse processo é a cooptação, por via de discursos pedagógicos, da grafitagem por parte do Estado, que investe, por exemplo, em oficinas para "transformar" pichadores em grafiteiros ${ }^{4}$.

Apesar desses investimentos nos grupos que realizam Pichação ou Grafite, com o intuito de transformar essas formas de intervenção segundo uma lógica de Arte institucionalizada, algumas pesquisas mostram que o movimento de aproximação a uma ideia erudita de produção artística não é um consenso e nem objetivo da maioria dos integrantes destes coletivos em Porto Alegre (Hamann, Maracci-Cardoso, Tedesco, \& Pizzinato, 2013; Oliveira-Machado \& Pizzinato, 2015). O movimento de institucionalização artística da Pichação e do Grafite e, portanto, de sua institucionalização nos círculos legitimados de produção, não está imune às divergências. Um dos principais aspectos é o flerte com situações delitivas e de transgressão ser um fundamento das intervenções. Tais dimensões também compõem as compreensões e possibilidades de exercício de poder nos espaços da Pichação e do Grafite, exigindo um alargamento da noção de Arte ou a legitimação de um campo comunicativo que se baseia também no risco e na possibilidade de transgressão. 
Nesse sentido, compreende-se que este campo de discussão pode se inserir em um marco político de estudo e se situaria em um espaço fronteiriço, intrinsecamente comunicacional, de sensibilidade e atribuições de sentido como as trabalhadas pelo filósofo Jacques Rancière (2009) quando concebe a noção de "partilha do sensível". Partilha, aqui, tomada como dimensão do comum, permite o entendimento de espaços de interação, relação, moralidade, legitimidade e investimento diferenciado em um determinado contexto social. Nos termos de Rancière:

a partilha do sensível faz ver quem pode tomar parte no comum em função daquilo que faz, do tempo e do espaço em que essa atividade se exerce. Assim, ter essa ou aquela 'ocupação' define competências ou incompetências para o comum. (Rancière, 2009, p. 16)

Em relação ao campo artístico - também foco da analítica do filósofo francês em relação à partilha do sensível - essa partilha cria um espaço de legitimidade dentro do que se entende tradicionalmente por Arte em função das relações entre duas formas de se pensar a Arte: os regimes poético e ético (Rancière, 2009). Ao passo em que o regime Ético atuaria na seleção de imagens de teor pedagógico (ele não delimita o objeto artístico), o regime Poético seleciona as formas de criação artística baseando-se no princípio inclusivo da mimese - resultando em um objeto artístico viabilizado em alguma forma de expressão (pintura, música, escultura, etc). É da/na articulação entre esses dois regimes que se constitui um regime de visualidade passível de ser chamado e nomeado tradicionalmente por "Arte".

Por ação desses dois regimes de relação cultural, efetiva-se uma seleção de fazeres e práticas artísticas pelas quais se desencadeia um determinado campo de visibilidade e de disputa de possibilidades - ou seja, o campo político. Rancière compreende a política como um regime de sensorialidade, uma "atividade que reconfigura os enquadramentos sensíveis no seio dos quais se definem objetos comuns" (Rancière, 2009, p. 90). Essa forma de uma atividade que se dá quando se evidencia um não dito, um não visto - quando se lança um olhar sobre algo/alguém à margem da configuração sensível tradicional - explicita a prática política via o que Rancière nomeia por dissenso. A política, portanto, pode ser vista como uma alteração, redistribuição das competências e incompetências. Equivale dizer que nela põe-se em cheque questões que porventura podem ser apresentadas como naturalizadas na vida em sociedade e que se encontram sustentadas por mecanismos de controle social e do uso constante e compulsório de uma normativa, a qual se caracteriza por um poder policial.
$\mathrm{Na}$ esteira das problematizações desse filósofo francês, a Política e a Arte possuiriam uma possibilidade de contato através do dissenso - o que, no campo artístico, possui relação com um terceiro regime de pensar a Arte, nomeado por regime Estético. Esse se caracterizaria por uma desconexão de três níveis do regime de pensamento Ético/Poético: as formas sensíveis (significações que nelas podemos ler e os efeitos que podem produzir); as formas de sua produção; e os fins sociais a que ela se destina. Dito de outra forma, a ocorrência de um objeto artístico no qual não seja possível o estabelecimento de relações de causa-efeito, de teores pedagógicos e que prescinda do princípio da mímese, central ao Regime Poético de Arte (Rancière, 2009). A política ocorreria em conjunto com o regime Estético, reconfigurando a experiência sensível por meio do dissenso.

Esse embate político tensiona diretamente a discussão sobre as intervenções visuais urbanas. Mostra-se como uma possibilidade privilegiada de compreender determinadas nuances, regimes de sensibilidade, que compõem as formas de ocupação e vida na cidade. Portanto, tentando compreender parte dos posicionamentos e encontros que situam o fenômeno das intervenções visuais na cidade de Porto Alegre com o referido aporte, este estudo se debruça sobre as considerações de recepção e significação dos grafismos urbanos nesta cidade. Considerando a dinâmica discursiva empreendida neste contexto comunicacional, o presente artigo procura através de narrativas de habitantes da cidade que não se identificam como artistas, ou praticantes do Grafite e da Pichação, compreender as atribuições morais às formas de intervenção visual urbana, especialmente as dinâmicas de autorização e legitimidade que se constituem nesse processo de atribuição de sentidos na ocupação visual das cidades.

\section{Método}

Neste estudo, 21 pessoas foram entrevistadas em locais públicos de Porto Alegre. Foram entrevistas realizadas por conveniência e desenvolvidas com base em perguntas gerativas e com recurso de fotografias. Foram utilizadas três fotografias, escolhidas por serem intervenções presentes no contexto urbano de Porto Alegre, respectivamente de Grafite, Arte visual chancelada e Pichação. O modelo de Arte Chancelada escolhido foi o da Cow Parade, propositalmente por adquirir popularidade no Brasil e, particularmente, na cidade de Porto Alegre. O evento teve versões em 55 cidades do mundo e forte divulgação na mídia local, de modo que congrega visibilidade mundial e 
características locais de produção - especificadas pela escolha de artistas locais para a produção das obras.

\section{Figura 1. Exemplos de grafismos urbanos apresentados aos participantes}

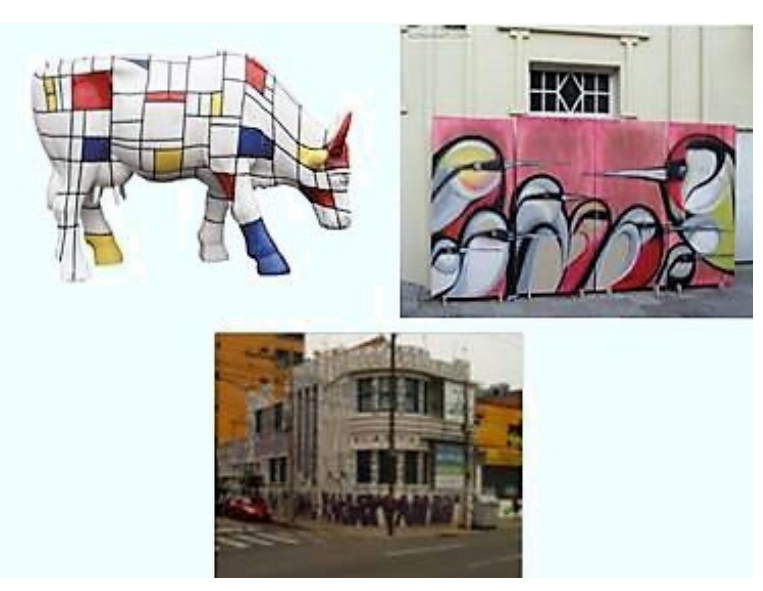

Por meio de fotografias como essas, procurouse solicitar aos passantes que expusessem as questões relevantes para si a respeito das imagens adotando três posições. Inicialmente a posição de Espectador, ou seja, como alguém que não realiza qualquer uma das intervenções urbanas apresentadas; posteriormente a posição Poder Público, ou seja, como alguém com autoridade legal para falar sobre requisitos necessários para a realização de cada intervenção representada nas fotografias; e, por último, a pessoa é convidada a argumentar como possível Criador/a das obras/ ações considerando as facilidades e obstáculos para a realização das referidas intervenções. As perguntas e as solicitações tinham como objetivo convidar os/as participantes a se imaginarem em diferentes posições, dando ensejo à possibilidade de refletirem acerca de conflitos, dissidências, consonâncias, evitações etc. que ocorrem em exercícios de alteridade. Não se estabeleceu um tempo específico de entrevista, como indicado em literatura especializada (Flick, 2009). As entrevistas geradas foram gravadas em áudio e transcritas para posterior análise e tiveram a duração média de 30 minutos.

Para análise, os conceitos teóricos foram debatidos à luz das experiências de campo, de modo que os discursos de legitimação e reconhecimento de objetos nomeados por "Arte", pelos participantes, são condicionados por processos localizados historicamente, recebendo acepções e práticas diversas em função de fatores macrossociais (políticos, culturais, econômicos, sociais) e microssociais (questões plásticas, temas eleitos, usos de materiais).

\section{Resultados e discussão}

A partir das entrevistas realizadas, foi possível traçar um mapa de significados atribuídos aos três meios de intervenção urbana ${ }^{5}$. Por meio das falas dos/as entrevistados/as elaboramos, sob a forma de um esquema, uma figura que indica a relação destas dimensões de produção cultural e significados que qualificam e estabelecem campos de diferenciação interna. Após apresentar as principais características que figuraram em cada um dos tipos de intervenção, discutiremos os eixos que sustentavam estas dinâmicas de significado nas narrativas e que permitiram sintetizar a dinâmica autorização/legitimidade: as dimensões consistência do ato, uso dos espaços, linguagem comum e a noção de representatividade, assim como as articulações desses significados dentro de uma perspectiva de partilha do sensível.

\section{Figura 2. Mapa conceitual das significações dos participantes}

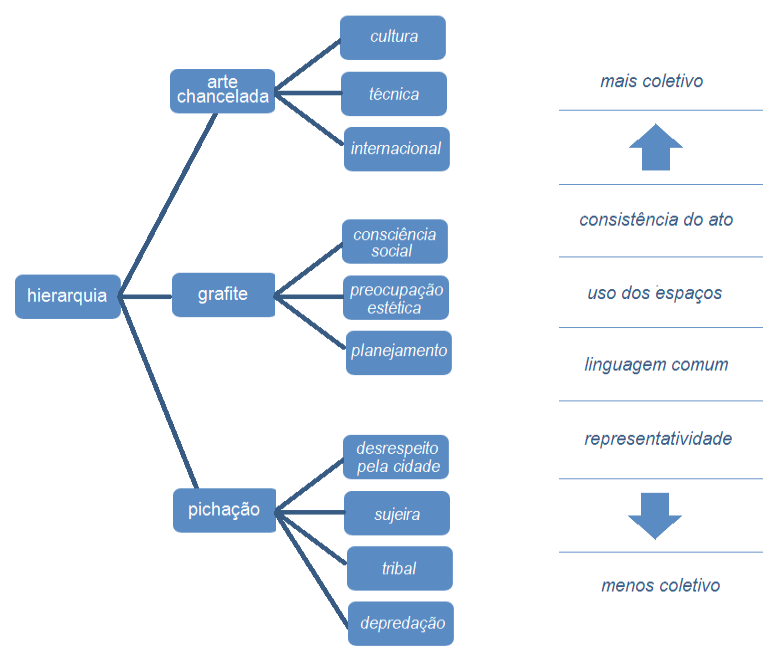

No tocante à Arte Chancelada, as entrevistas deram ensejo para três noções que se encontram imbricadas: cultura, técnica e caráter internacional. A técnica figura nas entrevistas enquanto atributo e reconhecimento de uma "obra de Arte"; nota-se que o conceito técnica engloba questões plásticas em relação à forma, cor, traço, desenho, conteúdo, volume, materiais. Esses aspectos se encontram presentes nas entrevistas da população participante, sendo referida em muitos casos como certo "estilo". A relação estabelecida pela população quanto à técnica não pareceu desvinculada de uma noção de "tecnologia", na qual os materiais utilizados possuíam uma relevância na obra realizada. Dessa forma, 
segundos os/as participantes, os materiais relacionados à Arte Chancelada (como, por exemplo, tipos de tinta, utilização de verniz na superfície da estátua de vaca) são compreendidos como mais "tecnológicos" e superiores aos sprays do Grafite e "rolinhos" da Pichação. Com efeito, os materiais disponíveis para a realização de alguma intervenção gráfica se mostram significativos para o reconhecimento de determinada "obra". A técnica, nesse caso, parece englobar as práticas existentes em um continuum, no qual a Arte Chancelada figura como superior em função da tecnologia empregada.

A noção de "cultura" para os (as) participantes, por outro lado, remete a aspectos relacionados com erudição - compreendida como um conhecimento superior no tocante à linguagem artística utilizada. A associação entre "obra de Arte" como representativa de uma cultura implica o agente dessa obra, compreendido como alguém cultivado, contendo informações e conhecimentos que o diferenciam do restante da população; nomeadamente, a cultura delimita o/a artista destacando-o/a do tecido social. Com efeito, os/as participantes reiteraram noções nas quais a figura do "Artista" aparecia associada com um conhecimento superior, de difícil acesso e que se comprovava mediante suas intervenções suas obras. Não raro, as associações entre "artista" e "legitimação da intervenção" apareciam juntas, ainda que os/as participantes, ao comentarem as intervenções consideradas por eles/as como "obra de Arte", não soubessem expressar o motivo pelo qual consideravam a intervenção uma "obra". Nesse particular, os/as participantes afirmaram que, embora não soubessem qual mensagem a obra passava (reiterando a noção de que uma obra necessariamente traz uma mensagem), ela era legítima por ter sido feita pelo/a "artista", ou seja, como se a posição de artista teoricamente fosse equivalente a de detentor/a último/a de um conhecimento inteligível nesse campo. Essa concepção de artista nos remete à leitura que Rancière (2014, p. 138) faz da definição aristotélica de cidadão, onde o sujeito se define por tomar parte de um modo de agir específico (o do arkhêin) e pelo padecer que corresponde a esse agir. Em outras palavras, é a própria processualidade do reconhecimento artístico que cria a definição do artista e a ele/ela próprio.

A internacionalização, por sua vez, estaria atrelada ao reconhecimento; a obra ser internacional seria prova de sua validade, legitimação no campo artístico, especialmente quando veiculada na mídia hegemônica, que chancela seu valor, reforçando, assim, seu status. Os/as entrevistados/as reiteraram noções de valoração artística e de comunicação associadas ao fenômeno da internacionalização. Ser internacional parece estar relacionado a uma maior carga valorativa da obra realizada, bem como apanágio e legitimação de seu valor representativo junto ao estatuto da Arte. Ligado aos veículos de comunicação de massa, o objeto de Arte atinge o estatuto de comunicação neutra, sendo passível de reconhecimento e valoração para além do contexto no qual fora gerado, especialmente, em nosso caso, revalidando a lógica das políticas coloniais de subjetivação, posto que esse "internacional" quase sempre se refere aos centros culturais do hemisfério norte, marcadamente a Europa.

O Grafite, de maneira geral, aparece relacionado a três conceitos: planejamento, preocupação "estética" e consciência social. No tocante ao planejamento da intervenção Grafite a população participante oscila entre compreender o Grafite como produto de uma elaboração por parte do/a grafiteiro/a ou como produto da "inspiração momentânea". O que figura, nessa situação, é um processo comparativo, no qual, em relação à cow parade, o Grafite aparece como inspiração mais momentânea, fugaz e irresponsável e, em relação à Pichação, aparece como resultado de uma organização superior, seja em seus aspectos formais, seja nos locais onde é realizado.

$\mathrm{Na}$ diferenciação operada nas narrativas, a associação entre uma maior organização por parte do Grafite na exposição de seus temas e conteúdos, bem como na execução da intervenção, figuraram como distinção entre essa prática e a Pichação. Ao reiterarem que o Grafite tem um caráter de maior "organização", explicita-se uma noção de "ordem", que operaria tanto no/a grafiteiro/a quanto na intervenção realizada. Assim, segundo uma fala de um dos participantes, o pichador picha para "mostrar que está acima da lei", ou seja, alguém externo à partilha, enquanto o grafiteiro, segundo ele, teria um planejamento, suporia uma sujeição ao ordenamento para a execução da intervenção: "ele não fez isso ai em 10 minutos". Tal manifestação também nos remete à "terceira tese" de Rancière (2014) sobre a política, quando a concebe enquanto uma ruptura da lógica específica da arkhé. Em outras palavras, "ela não supõe apenas a ruptura da distribuição <normal $>$ das posições entre aqueles que exercem um poder e aqueles a que ele se submete, mas também uma ruptura com a ideia de que há disposições que definem um <próprio> dessas posições" (p. 140). Assim, o Grafite coloca em questão a essencialização da definição de artista pelo domínio da técnica, pondo em manifesto que a concepção de sensibilidade artística é uma construção política de estética.

No que se refere à preocupação "estética", em grande parte das entrevistas os/as participantes reiteram uma noção de "estético" associado a 
uma expressão com maior ou menor proximidade à ideia de Arte Chancelada. Os/as transeuntes diferenciavam o Grafite das outras intervenções relacionando a preocupação "estética" com códigos de reconhecimento e compreensão do grafismo realizado, bem como relacionavam a intervenção com sentimentos como "esperança" ou "amor" sendo o Grafite fruto da "expressão do artista" que quer "passar uma mensagem". Com isso, o Grafite aparece como uma intervenção urbana definida nas narrativas como de caráter mais "coletivo", de reconhecimento e identificação mais direta e objetiva. Nesse sentido, o fato de a maioria das imagens veiculadas nos Grafites ser composta por imagens com fortes características figurativas aliadas ao uso de elementos plásticos de composição - como uso de cores ou volume - é aspecto decisivo dessa suposta objetividade visual.

Nesse aspecto, a legitimação das intervenções consideradas Grafites pelos(as) interlocutores(as) está relacionado a um campo identificado como pessoal, particular, homogêneo mas universal. Dele pode-se notar de uma forma geral que os argumentos utilizados para sustentar essa aceitação se valem de elementos dispersos, fragmentários e organizados de forma nem sempre coerente - de modo que a expressão dos mesmos se aproxima muito mais da reprodução de argumentos morais presentes na mídia do que de uma articulação crítica em relação a uma forma de expressão e composição de arte.

A consciência social, por sua vez, aparece relacionada a uma ideia de "cuidado com a cidade", tangenciando aspectos como limpeza, higiene, moderação e beleza - possuindo vínculos com uma pedagogia e "moralização do ato artístico" em relação a essas ocupações visuais. A cidade aparece nas narrativas como uma instância superior aos seus habitantes, no qual a "beleza" atribuída ao Grafite guarda aspectos com uma noção de "respeito" à urbe. Além disso, nota-se que a noção de cidade apresentada remete a uma ideia totalizadora de um organismo fechado, homogêneo e governado por leis externas a ele. Em consonância com os processos de gentrificação e de espetacularização urbana, os/as participantes, ao se referirem a Porto Alegre como distante dos/as mesmos/as, expressaram uma cidade cada vez menos participativa e cada vez mais orientada, politicamente, por uma lógica liberal e capitalista, enfatizando o poder de consumo como equivalente à cidadania. Assim, em algumas falas essa lógica capitalista orienta uma concepção de cidade não como um espaço de uso comum - público para todas as pessoas -, mas para algumas pessoas. Essa concepção contribui para uma visão do Grafite como "mais cuidadoso com a cidade", identificado como intervenção de maior organização e menos dissidência formal quando comparada com a Pichação.

Contribui a esse processo o fato de o Grafite ser entendido muitas vezes como detentor da capacidade de "embelezar" o local onde for realizado. Nesse sentido, pode-se notar com propriedade um discurso de incentivo e propaganda entre: a veiculação de matérias pró-grafite em jornais de grande circulação, a ação do Poder Público ao disponibilizar áreas determinadas para a prática do Grafite e a utilização desse enquanto chamariz em fachadas de lojas comerciais. Reunidos, esses processos acabam por incrementar maior visibilidade à prática deste grafismo, havendo a possibilidade de associação entre essa expressão gráfica e a utilização de uma relação maniqueísta em relação à Pichação - dando ensejo a expressões valorativas de "certo"/"errado", "bonito"/"feio".

O uso do Grafite ou como instrumento artístico pedagógico ou junto a uma lógica de propaganda de estabelecimentos comerciais expressa um movimento de cooptação assimilativo por parte desse grafismo a uma linguagem artística mais legitimada. Do regime ético, ainda que a princípio qualquer imagem seja passível de reprodução em forma de Grafite, as imagens utilizadas com frequência variam de animais, símbolos relativos às tradições culturais do local no qual é realizado ou personagens de conhecimento comum. Do regime poético, o uso de materiais como tintas e spray, reconhecidos como instrumentos hábeis à representação poética de temas eleitos, prestam-se a uma representação das formas sensíveis eleitas. $\mathrm{O}$ uso que se faz no Grafite no que concerne a ambos os regimes o aproxima do campo legitimado como Arte.

Já no que se refere à Pichação, nota-se para os/ as participantes da pesquisa a intersecção entre o que eles/as consideram como uma forma de "comunicação grupal", sua prática na urbe e a comparação com o Grafite e/ou com a Arte Chancelada resulta em uma avaliação negativa desse grafismo. Assim, desrespeito pela cidade, sujeira, depredação e comunicação tribal são referências por parte dos/ as participantes cuja prevalência faz-se notar. Os sentidos atribuídos a essa prática, nos quais a relação entre sujeira e depredação é muito calcada em uma moralidade do ato, se aproximam de uma ideia de "má educação" por parte de seus/suas praticantes. O reiterado desrespeito pela cidade é justificado por uma visão na qual a cidade figura como uma entidade sacralizada, cujos habitantes devem adaptar-se, onde se idealiza a subordinação. A Pichação, nesse aspecto, aparenta possuir efeitos diferentes: no tocante a esses grafismos urbanos, a dicotomia maniqueísta é 
presente, o que deixa implícita uma visão moralista acerca da Pichação. Nessa, seus/suas praticantes constam como indisciplinados/as e necessitados/ as de um processo de tutela/educação/pedagogia para que sua intervenção seja menos "agressiva" e mais "adequada" para o espaço público, a que, em palavras de Rancière (2009), se inscreveria na noção de educação estética (p. 39), que além de hierarquizar sensibilidades fixa essa hierarquização (dominação e servidão) em um caráter ontológico. Assim, poder-seia dizer que essa "rebeldia estética" que propõem as formas não legitimadas de produção artístico-visual também produz uma revolução política no regime de sensibilidade artística, como mais uma realização sensível de uma dada humanidade, existindo ainda que somente enquanto ideia (Rancière, 2009, p. 40).

Esse aspecto parece ser exemplificado pelas vezes nas quais o ato da Pichação aparecia diminuído, desprovido de significação (apenas como demonstração de que era possível pichar); segundo alguns dos entrevistados, ou o pichador age de forma insolente ("só picha para mostrar que esta acima da lei") ou seu ato é compreendido sob um poder verticalizado ("tu não podes... tu não tá acima da lei para fazer isso"). $\mathrm{O}$ ato de pichar é frequentemente interpretado como necessariamente esvaziado de sentido, mas é importante observar que, nas narrativas, isso se dá simultâneo a outras questões: a noção de que essa prática não é autorizada legalmente serve para os/as participantes da pesquisa como argumento corriqueiro para uma posição rígida em relação à pessoa que picha. A lei aparece como um regulador, um teto de práticas sociais que podem ocorrer - ou, dito de outra forma, que estão autorizadas a acontecer. A lei é associada a uma ordem, ao correto, polido - que quando não é cumprida pelo/a pichador/a o/a alça a uma categoria de alguém que não compartilha de um comum de valores - o que corrobora para a construção de personagem social dissidente, já que no campo narrativo das entrevistas nem a Arte urbana chancelada e nem o Grafite fomentaram esse tipo de associação.

Nesse particular, a analítica proposta por Rancière nas relações entre Arte e Política se mostra potente. O regime policial mantém uma distribuição de corpos, de instituições e das relações estabelecidas entre ambos configurando um regime de sensorialidade na experiência comum. Essa configuração pode sofrer uma ruptura, ou seja, ser rompida mediante a ação de um agente cuja competência para uma determinada atividade não se inscrevia anteriormente. Nesse processo, se torna possível verificar a igualdade entre os agentes envolvidos, bem como reordenar a distribuição de competências e funções dando ensejo a uma nova configuração sensível na experiência comum(Rancière,
1996). Em relação à arte, essa ruptura ocorreria via a suspensão propiciada pelo regime Estético; pela política, pela reconfiguração do sensível (Rancière, 2009). No momento no qual existe a possibilidade de inscrição pela cidade de frases, tag's, nomes, mensagens via picho dá-se ensejo à verificação de que a pichação também possui materiais próprios, formas de ação e prática coesas, suportes (edifícios, muros) e lógicas próprias à prática da pichação. $\mathrm{O}$ dissenso e, por conseguinte, a reconfiguração do sensível, se demonstra pelo picho e seus/suas praticantes/as que eles também podem, se quiserem, tomar parte das discussões referentes à Arte e a Cidade. Abre-se a possibilidade de problematização da configuração das competências de quem pode realizar um grafismo urbano. Além disso, evidencia um coletivo - mesmo quando mantido anônimo - de habitantes com práticas urbanas que mobilizam mais práticas higienistas e de segregação urbana (via pichação, sobretudo).

A deslegitimação do autor da Pichação, reiterada na necessidade de pedagogização desse mesmo autor - visto em documentos governamentais como homem, jovem, negro e desordeiro - reforçam a ideia de que a deslegitimação da prática da Pichação também está atrelada a questões como gênero e raça - mesmo que estudo em Porto Alegre tenha mostrado uma pluralidade concorrente à percepção governamental (Hamann, Maracci-Cardoso, Tedesco, \& Pizzinato, 2013). Nesse sentido, os/as participantes da pesquisa, ao reiterarem que os atores da Pichação depredam a cidade, são "desorganizados", não possuem "consciência social" e "sujam" o meio urbano, reforçam não só uma distinção moral dentro dos grafismos como também organizam uma imagem estereotipada de seus/suas praticantes com forte viés relacional: por ser o ator da Pichação "mal-educado" e "desordeiro", sua expressão gráfica é "suja" e "feia". Ao reforçarem e se referirem à Pichação como um ato "desprovido de sentido", se retira a possível carga política desse grafismo urbano quando realizado em locais de grande visibilidade e nos quais os processos de espetacularização são mais acentuados, deixando marcas de profanação desses espaços sacralizados - especialmente os privados - da cidade (Jacques, 2008).

Frente a essa lógica de organização, a existência da Pichação também pode ser interpretada como instauradora de uma zona de tensão (Jacques, 2010) na qual se evidencia um conflito entre regimes de diferentes sensibilidades sócio-sensoriais, um tensionamento envolvendo práticas legitimadas e não legitimadas, tanto em sua dimensão estética quanto política. $\mathrm{Na}$ esteira do sentido atribuído por Rancière (1996) à palavra política, ressalta-se que a dimensão política da Pichação não é inerente a sua prática, resultando 
em ato político na intersecção de fatores como local, uso de espaço, tipo de Pichação, significação atribuída ao grafismo etc. Dessa forma, no momento no qual as cidades contemporâneas são apresentadas sob a égide da lógica de venda-consumo de seus espaços públicos, a prática da Pichação ser associada à ilegalidade sendo denominada como "vandalismo" - corrobora uma dimensão do que é nocivo ao patrimônio. Nesse particular, a Pichação recebe um tratamento de doença social - necessitando, portanto, ser extirpada da cidade, posto estar em conflito com os processos de venda dos espaços púbicos.

No tocante aos aspectos comucacionais envolvidos na prática da Pichação, se, para as pessoas entrevistadas, na Arte Chancelada e no Grafite havia uma comunicação universal - os códigos veiculados na Pichação soam aos/as transeuntes como uma comunicação tribal; o fato do termo "tribal" ter aparecido com ênfase notável remete a uma visão na qual a dicotomia civilizado-bárbaro/selvagem é presente. Com efeito, ainda que seja reconhecido e aceito que a Pichação seja uma forma de comunicação entre um grupo de pessoas ou com a sociedade em geral (os/as participantes concordam com essa afirmação) ela é entendida sob viés negativo, individual, egoísta e menos "coletivo".

Em contraponto, outras formas de comunicação na urbe que não entendidas como expressões artísticas não são vistas como uma comunicação entre tribos. A partir da noção especulativa e comercial atual percebese que os anúncios publicitários e de marketing são permitidos com mais frequência no ambiente da cidade, porquanto remetem a uma lógica de consumo e de venda a qual é assimilada e reproduzida nos mais diversos âmbitos da vida social. Por vezes, essa forma de comunicação figura isenta de maiores críticas, com nível de comunicação e de abrangência próximos ao universalismo da Arte Chancelada. Questionados/as sobre o que achavam sobre esses tipos de anúncios na urbe, os/as participantes se referiam aos mesmos como "normais" e "naturais", constituintes de processos de compra e venda.

Nas entrevistas, as intervenções visuais urbanas elencadas foram entendidas como "mais coletivas" ou "menos coletivas". Os discursos de legitimação e/ou autorização vinculados às intervenções "mais coletivas" foram, de maneira geral, positivos - ao passo que, em relação às intervenções "menos coletivas", mais discursos negativos foram vinculados. Dessa maneira, pode-se chegar a uma dimensão de entendimento e recepção por parte da população de atividades compreendidas como detentoras de uma linguagem compartilhada e representativa - que, por consequência, é mais aceita, legítima. Está imbricada a isso uma noção de representatividade como organizadora da hierarquia entre as intervenções. Ser representativo, nesse caso, parte de uma atribuição e investimento em aspectos como: consciência do ato, linguagem utilizada e espaço na qual a intervenção fora realizada. Quando reunidos para análise de alguma obra de Arte Chancelada, Grafite ou Pichação, esses aspectos avaliam a intervenção como mais ou menos representativa para um maior número de pessoas.

A hierarquia existente entre os três campos elencados (Arte Chancelada, Grafite e Pichação) é organizada pela população de forma que, ainda que as pessoas entrem em contato com pichações com maior frequência do que obras de arte, as pichações são entendidas como menos representativas, posto que seus atores, materiais, locais de realização etc. se valem de aspectos que se encontram fora do campo de visibilidade e legitimação artística, engendrando práticas policialescas e uma partilha do sensível que não obedece completamente à materialidade cotidiana.

Para Rancière (1996), a condição policialesca se estabelece por um conjunto de diferentes processos que mantém uma configuração sensível já realizada, de modo que os locais, funções e papéis distribuídos podem ser resguardados e, simultaneamente, legitimados coletivamente (Rancière, 1996). Esse policiamento pode ocorrer de várias formas, podendo existir de maneira explícita e violenta como em uma agressão, ou por maneiras mais sutis como naturalização de comportamentos, ações ou modos de viver. Nesse sentindo, compreende-se da fala de um dos participantes esse fenômeno de polícia em suas instâncias artístico-normativa (1); questão de planejamento e organização (2); autorização individual (3) e autorização jurídica (4):

Ah, primeiro que quem para fazer uma imagem dessas tem que ser um artista (1), né, nesse sentido. Então ele precisa de tempo para fazer, com certeza ele teve um planejamento (2) pra fazer isso aí.. As outras não, as outras eu acho que ele só chegou lá e pichou pra mostrar que podia pichar... eu acho que seria isso; nada contra né, mas acho que assim ó. Acho que as outras assim tu não tem o consentimento da pessoa que é o particular que é dono (3) ou algo público entende, tu não pode... tu não tá acima da lei (4) para poder fazer esse tipo de coisa. (D., 27 anos)

A partir desse pequeno trecho depreende-se que o conjunto dos enunciados presentes configura uma "estética de vida" na qual a possibilidade de uma prática dissidente é tolhida e esvaziada por um discurso policial que reitera o arranjo sensível existente e moraliza um ato gráfico potencialmente político. É no 
campo dialógico que se formam os regimes perceptivos de possibilidades artísticas, ou seja, um conhecimento, um saber sobre determinado assunto aliado às práticas, regras de conduta, normas, dispositivos recursivos de ação, tempos, espaços, funções - linguagens técnicas - e, sobretudo, de um sujeito de enunciação, que se permite pensar como autor da prática em questão. Um regime de sensibilidade, nesse sentido, é mais do que uma forma de dar visibilidade ao mundo, de apresentálo, mostrá-lo, explicá-lo; é uma maneira de inserção e vivência em um determinado modo de ser, regulador de corporeidades, sensações e afetos.

\section{Considerações finais}

No contexto desta pesquisa, os/as participantes se valeram da noção de autorização como recurso de polícia dos fazeres e dos modos de ser na cidade. Utilizando-a como um código que policia as ações dos habitantes da cidade, essa noção marginaliza o caráter político e transgressor que a Pichação pode comportar, esvaziando-a e reificando-a como um ato delitivo. Com efeito, não raro a lei apareceu associada como forma de punição e de controle sobre os atores da Pichação e sobre seus locais de realização, estando imbricada com a autorização para que essa aconteça em última instância, permitindo e legitimando que ela se desloque de um regime a outro, ou seja, figurando como modo recursivo e visível de arte de uma população marginalizada por diversos mecanismos de ação.

Percebe-se, nas falas dos(as) participantes, a relação estabelecida entre esse discurso jurídico com o discurso artístico. Nesse particular, o sistema de representação artístico-estético aparece como um mecanismo de repressão da Pichação, deslegitimando-a por meio de outro discurso: o jurídico-criminal. Ambos os discursos figuram como agentes de regulação, de legitimação das práticas de ocupação visual da cidade. É patente que a Pichação - bem como seus atores - não se encontram no quadro oficial do corpo artístico e de conduta moral e valorativa do consenso criado pelo regime do sensível (compulsório) vigente.

Essa "estética" comporta regimes de visibilidade, ou, dito de outra forma, formas de se ver/fazer/consumir o visual, de se fazer e criar objetos apreciáveis. Essa representação guarda uma analogia/semelhança com uma comunidade também hierarquizada, entre aquele que detém a palavra e competência para se ocupar desse cargo de enunciação - e aqueles que não possuem essa competência. Nesse sentido, manifestações urbanas sugerem que seus atores utilizam esse "espaço potente" como forma de apropriação e de ocupação, de autoria. Valendo-se das fachadas dos edifícios, dos muros e paredes - cabines de telefone ou mesmo paradas de ônibus - as Pichações, em especial, não são e nem precisam disputar um sentido artístico-estético majoritário: são marcas de itinerários e percursos que entram em conflito com outros processos de homogeneização urbana, podendo ser compreendidas enquanto possibilidades de ação e resistência contemporânea. Essas práticas falam de relações com a cidade, de modos de habitá-la, de usar, normatizar e transgredir seus espaços.

\section{Notas}

1 Arte Chancelada é um termo utilizado, neste estudo, a partir do processo de pesquisa elaborado. Propõe-se a dar ênfase a intervenções que têm uma forte marca de autorização, autenticação ou comprovação de validade por via estatal ou pelos cânones tradicionais da Arte.

2 Nos primeiros dias de 2017, após destruir conhecidos murais de grafite na Avenida 23 de Maio, a prefeitura de São Paulo propõe a criação de um programa para promoção de grafiteiros e muralistas e a criação do Museu de Arte de Rua. Além dos beneficiados pelo programa serem escolhidos por meio de uma seleção de responsabilidade de uma comissão da Secretaria Municipal de Cultura operada por "artistas, críticos e especialistas no assunto" (Toledo, 2017), pichadores(as) não são beneficiários(as) possíveis. Esse tipo de cooptação como forma de pedagogia moralista é um processo recorrente em diversas cidades brasileiras (Hamann, Maracci-Cardoso, Tedesco, \& Pizzinato, 2013).

3 Como exemplo, a notícia veiculada no jornal Zero Hora de Porto Alegre: "Câmara aprova projeto que especifica a punição para pichadores". Recuperado de http://zh.clicrbs. com.br/rs/porto-alegre/noticia/2015/08/camara-aprovaprojeto-que-especifica-a-punicao-a-pichadores-4828360. $\underline{\mathrm{html}}$

4 Muitos destes aspectos pedagógicos podem ser contemplados no site da Secretaria de Segurança Pública do Distrito Federal, através do documento: "Como identificar um pichador?" Recuperado de http://www.ssp. df.gov.br/servicos/programas-comunitarios/picasso-naopichava/276-cartilha-como-identificar-um-pichador.html

Os termos, apresentados no decorrer deste artigo, são homônimos aos utilizados pelos participantes da pesquisa. Sublinhado: termos considerados na análise como eixos, nódulos vinculados a categorias menores. Entre parênteses: termos relacionados a estes eixos principais.

\section{Referências}

Bastianello, T. A. B. (2015). Grafismos urbanos: mensagens políticas em grafites e pichações na região central de Porto Alegre (2013-2014). Dissertação de Mestrado, Programa de Pós-graduação em Comunicação, Universidade do Vale do Rio dos Sinos, São Leopoldo, RS.

Brito, F. D. \& Jacques, P. B. (2009). Corpocidade: arte enquanto micro-resistência urbana. Fractal: Revista de Psicologia, 21(2), 337-350. 
Debord, G. (1997). A sociedade do espetáculo. Rio de Janeiro: Contraponto.

Flick, U. (2009). Desenho da pesquisa qualitativa. Porto Alegre: Artmed.

Hamann, C., Maracci-Cardoso, J. G., Tedesco, P. C., \& Pizzinato, A. (2013). Entre o público e o privado: discurso de mulheres em movimentos de grafite. Ex Aequo (Oeiras), 28(1), 45-58.

Jacques, P. B. (2008). Corpografias Urbanas. Arquitextos, 93. Recuperado de http://www.vitruvius.com.br/revistas/read/ arquitextos/08.093/165

Jacques, P. B. (2010). Zonas de tensão: em busca de microresistências urbanas. In P. B. Jacques \& F. D. Brito (Orgs.), Corpocidade: debates, ações e articulações (pp. 42-53). Salvador: EDUFBA.

Larruscahim, P. G. \& Schweuizer, P. (2014). A criminalização da pichação como cultura popular na metrópole brasileira na virada para o século XX. Revista de Direitos e Garantias Fundamentais, 15(1), 13-32.

Leite, R. P. (2007). Contra-usos da cidade: lugares e espaço público na experiência urbana contemporânea. Campinas, SP: UNICAMP.

Munhoz, N. B. (2014). Pichadores de Florianópolis: memória e relações de grupo em meio a metrópole contemporânea. Trabalho de Conclusão de Curso de História, Centro de Filosofia e Ciências Humanas, Universidade Federal de Santa Catarina, Florianópolis, SC.

Oliveira-Machado, R. \& Pizzinato, A. (2015). Quem é da rua não é da calçada? Cenas da pixação em Porto Alegre. Athenea Digital, 15, 3-23.

Paixão, S. J. C. (2011). O meio é a paisagem: pichação e grafite como intervenções em São Paulo. Dissertação de Mestrado, Programa de Pós-graduação em Estética e História da Arte, Universidade de São Paulo, São Paulo.

Pena, J. S. \& Wan-Dall, O. A. (2012). Partilha e conflito no espaço público. In P. B. Jacques \& F. D. Brito (Orgs.), ReDObra (pp. 46-57). Salvador: EDUFBA.

Piccoli, F. (2014). Riscos rebeldes: notas etnográficas e criminológicas sobre a pichação. Dissertação de Mestrado, Programa de Pós-graduação em Ciências Criminais, Universidade Federal do Rio Grande do Sul, Porto Alegre, RS.

Rancière, J. (1996). O desentendimento. São Paulo: 34 Ltda.

Rancière, J. (2009). A partilha do sensivel. São Paulo: 34 Ltda. Rancière, J. (2014). Nas margens do político. Lisboa: KKYM.

Silva, E. L. (2010). A gente chega e se apropria do espaço! Graffiti e pichações demarcando espaços urbanos em Porto Alegre. Dissertação de Mestrado, Programa de Pósgraduação em Educação, Universidade Federal do Rio Grande do Sul, Porto Alegre, RS.
Toledo, L. F. (2017, 26 de janeiro). Após apagar grafite e pichação, Doria anuncia Museu de Arte de Rua. O Estado de São Paulo. Recuperado em 21 de Fevereiro de 2017. http:// sao-paulo.estadao.com.br/noticias/geral,doria-anunciaprograma-de-grafite-no-baixo-augusta-apos-apagar-muraisda-23-de-maio, 70001642437

Verano, P. N. (2013). Por uma politica cultural que dialogue com a cidade: o caso do encontro entre o MASP e o graffiti. (2008-2011). Dissertação de Mestrado, Programa de Pósgraduação em Ciência da Informação, Universidade de São Paulo, São Paulo.

Viegas, G. C. F. S. \& Saraiva, L. A. S. (2015). Discursos, práticas organizativas e pichação em Belo Horizonte. Revista de Administração Mackenzie, 16(5), 68-94.

Agência de fomento: CNPQ - Edital de Apoio à Pesquisa - Bolsas de Iniciação Científica 2011/2013 [PIBIC]: Projeto "Análise dialógica de narrativas visuais no espaço urbano de Porto Alegre"

Submissão em: 16/09/2016

Revisão em: 23/01/2017

Aceite em: 26/02/2017

Adolfo Pizzinato é professor da Escola de Humanidades

- Programas de Pós-graduação em Psicologia e Serviço Social - Pontifícia Universidade Católica do Rio Grande do Sul [PUCRS].

Endereço para correspondência: Programas de Pósgraduação em Psicologia/PUCRS. Av. Ipiranga, 6681. Partenon. CEP 90619-900. Porto Alegre/RS, Brasil.

E-mail: adolfopizzinato@hotmail.com

Pedro de Castro Tedesco é graduando em Psicologia na Pontifícia Universidade Católica do Rio Grande do Sul

[PUCRS].

E-mail: pedrocastro.tedesco@gmail.com

Cristiano Hamann é graduado em História pela ULBRA, mestre em Psicologia Social pela PUCRS e doutorando em Psicologia Social e Institucional na UFRGS. E-mail: chamann13@hotmail.com 